\title{
A Expansão da Rede Federal de Educação Profissional e Tecnológica e os Institutos Federais no Contexto Regional: Diálogos com o Desenvolvimento
}

\author{
The Educational and Technological Federal Network Expansion and the Federal \\ Institutes in the Regional Context: Development Dialogues
}

Luiz Augusto Caldas Pereira*

\begin{abstract}
Resumo: A proposta do artigo é analisar os efeitos da expansão da Rede Federal e da criação dos Institutos Federais e sua contribuição para o desenvolvimento considerando as possibilidades multi e transescalares, a partir do diálogo que potencializa intervenções a favor do desenvolvimento. Os conceitos de território, escalas e desenvolvimento, aqui apresentados na propositura de fundamentos teóricos, buscam sustentar os argumentos que conduzem às reflexões pretendidas. A Educação Profissional e Tecnológica e seu protagonismo nos processos de desenvolvimento são analisados sem desconsiderar autonomia, hierarquias e limites do poder subnacional, num gerenciamento autossustentável de seu futuro. Por fim, dentro das políticas de expansão da Rede Federal, aborda, em especial, os Institutos Federais e o papel estratégico que podem assumir numa proposição de desenvolvimento que fortaleça a cidadania.
\end{abstract}

Palavras-chave: Institutos Federais; Escalas; Territórios; Desenvolvimento.

\begin{abstract}
The purpose of this article is to analyze the effects of the expansion of the Federal Network and the creation of the Federal Institutes and their contribution to development considering multi and trans scalars' possibilities, from the dialogue that enhances interventions in favor of development. The concepts of territory, scales and development, presented here in the proposal of theoretical foundations, seek to sustain the arguments that lead to the intended reflections. The Professional and Technological Education and its protagonism in the development processes are analyzed without disregarding autonomy, hierarchies and limits of the subnational power, in a selfsustaining management of its future. Finally, within the Federal Network's expansion policies, it addresses, in particular, the Federal Institutes and the strategic role they can play in a development proposal that strengthens citizenship.
\end{abstract}

Key words: Federal Institutes; Scales; Territories; Development.

\footnotetext{
Professor e ex-reitor do Instituto Federal Fluminense (IFFluminense), RJ - Brasil. Doutorando em Planejamento Regional e Gestão de Cidades na Universidade Candido Mendes. E-mail: luizcaldas.iff@gmail.com.
} 


\section{Introdução}

Complexidade talvez seja uma das características que melhor traduza o debate em torno dos rumos do desenvolvimento que considera as alterações do capitalismo na travessia do século XX para o século XXI. Os diversos eventos que irrompem nesse período, marcado por um cenário de crises frequentes, resultaram nas alterações dos padrões produtivos que têm desafiado os especialistas na construção de métodos analíticos, capazes de explicar os fenômenos socioeconômicos e políticos iniciados nesse tempo.

No Brasil, numa estratégia de viés político e econômico, foram aplicados investimentos com vistas a um processo de desenvolvimento orientado pela hegemonia da industrialização. No entanto, o resultado de tais investimentos se traduziu num estágio bastante assimétrico produzindo, ao longo do tempo, desigualdades de diferentes naturezas: social, econômica, populacional, produtiva, regional etc.

As políticas de amortização dos impactos da crise e de tais assimetrias, por sua vez, mudam ao sabor das ideologias das orientações de cada governo, daí a importância da Educação em uma perspectiva crítica. As políticas voltadas para a Educação, a partir de 2003, em especial as referentes à Educação Profissional e Tecnológica (EPT), por exemplo, contribuíram para fortalecer o espaço regional no território. A criação da Rede Federal de EPT, por meio da Lei n 11.892 de 29 de dezembro de 2008 (LEI No 11892/2008), com suas Instituições ${ }^{\mathrm{i}}$ e sua capilaridade por todo o país, ampliou o acesso e as ofertas de formação profissional e tecnológica a jovens e adultos da classe trabalhadora e aprofundou o diálogo entre educação, produção de conhecimento e desenvolvimento. Por essa razão, neste artigo, levar-se-á em consideração a aproximação entre EPT e desenvolvimento. Nessa aproximação, alguns aspectos que marcam a complexidade dessa inter-relação serão considerados, dentre eles: a forma de contraposição da interpretação simples e linear que a situa no plano da causa e efeito, e a visão improcedente que ressalta um protagonismo da EPT na condução dos processos de trabalho, da mesma forma que negligencia os limites de poder das escalas subnacionais e suas diferentes representações em relação ao desenvolvimento. 
Para isso, recorreu-se às produções de alguns autores tais como Santos (2008), Brandão (2004, 2009) e Oliveira (2001), dentre outros, que não negam as possibilidades do subnacional, mas, chamam a atenção para a necessária ponderação sobre os riscos impostos ao propor o seu desenvolvimento, sem levar em consideração a existência de limites em face à existência de estruturas de poder que implicam hierarquias no campo macroeconômico e de decisões - já que o subnacional, nessa perspectiva, não tem poderes absolutos.

As questões que se colocam são: Qual o papel que podem assumir os Institutos Federais enquanto um dos atores na promoção do desenvolvimento? Quais são os limites e possibilidades de uma contribuição mais efetiva da Rede Federal à afirmação da dimensão regional nas políticas de desenvolvimento? Até que ponto a mais recente expansão da Rede Federal e a criação dos Institutos Federais contribuem para que a escala local sobressaia no contexto das políticas de desenvolvimento nacional? É possível cogitar, a partir das iniciativas que alcançaram as Instituições Federais de Educação Profissional e Tecnológica, no período 2003/2014, mudanças de realidades patenteadas pelo local?

Busca-se neste artigo incitar o debate que coloca em destaque intervenções com vistas ao desenvolvimento nos territórios, a aproximação e referência ao desenvolvimento e discutir que caminhos podem trilhar, ou que papel devem desempenhar os Institutos Federais a favor do desenvolvimento que reconheça as escalas subnacionais de forma crítica, ou seja, em um exercício em que reconheça os seus limites e perceba, nesse contexto, as possibilidades multi e transescalares. Inicialmente, aborda-se os conceitos de território e desenvolvimento sob a ótica das escalas, considerando que estas são dinâmicas, posto que construídas social e conflitivamente no embate relacional vis-à-vis outras escalas e, por isso, estão sempre em processo e em movimento.

O tema desenvolvimento está apresentado a partir de alguns debates e questões que se colocam na atualidade. Em relação ao desenvolvimento brasileiro, a análise segue numa abordagem sob a ótica da regionalização. Ocupa a centralidade do estudo a política de expansão da Rede Federal, considerando que é nesse aspecto que reside a contribuição que se pretende adicionar às reflexões sobre o papel fomentador e o 
compromisso das instituições que compõem essa Rede com o desenvolvimento de seus territórios. Importante desde já considerar que a expansão dessa Rede alcançou abrangência territorial capaz de ampliar possibilidades e potencialidades em favor de benefícios sociais e econômicos para o desenvolvimento.

\section{Território, escalas e desenvolvimento}

A temática do desenvolvimento do território e as possibilidades das escalas subnacionais prosperarem em projetos sociais e econômicos ganharam destaque no âmbito das discussões e formulações acadêmicas e políticas, especialmente nas últimas décadas, no curso das mudanças decorrentes da crise do padrão de acumulação capitalista inaugurado no pós-II Guerra Mundial. A complexidade que envolve esse debate não é trivial, a começar pelas diferenças de significações conceituais das categorias envolvidas: daí a importância da aproximação do assunto e dos posicionamentos em relação ao que se fala. Nesse sentido, aqui se renunciará a complementos ao termo desenvolvimento como forma de assumi-lo a partir de uma perspectiva mais ampla que comporte mudanças estruturais em múltiplas dimensões: econômica, social, ambiental e política.

A ideia de território discutida aqui está pautada no pensamento de Santos (2008, p. 137), que chama a atenção para a necessidade de se ultrapassar a noção de território, conforme nos legou a Modernidade: algo puro, muitas vezes, sequer tocado ao longo dos séculos, ao mesmo tempo base e fundamento definidor dos contornos e limites do Estado-Nação. Para ele, é o uso, e não o território em si, que o torna objeto da análise social. Segundo o teórico:

Trata-se de uma forma impura, um híbrido, uma noção que, por isso mesmo, carece de constante revisão histórica. O que ele tem de permanente é ser nosso quadro de vida. Seu entendimento é, pois, fundamental para afastar o risco de alienação, o risco da perda do sentido da existência individual e coletiva, o risco de renúncia ao futuro. (SANTOS, 2008, p. 137) 
Sobressai, na atualidade, conforme destaca uma parte significativa da produção teórica sobre a temática, uma exagerada expectativa sobre as possibilidades de as escalas subnacionais assumirem o protagonismo no processo de desenvolvimento. Desse ponto de vista, parece inquestionável a existência de um pressuposto: a autonomia dessas escalas, ou seja, a desconsideração das hierarquias, que no limite de suas circunscrições responde a todas as necessidades requeridas para a implementação das ações de desenvolvimento. Nesse sentido, ao articular diferentes representações sociais, econômicas e políticas vivifica-se, no território eleito, a instalação de uma dinâmica efetiva na perspectiva do desenvolvimento.

Segundo Brandão (2004, p. 58), na visão localista parece que o território, enquanto "expressão da condensação de forças sociais e políticas abstratas, se apresenta como alternativa ao Estado ('que se foi')". A ênfase no território e o destaque às potencialidades das escalas subnacionais nos processos de desenvolvimento escapa ao que se pretenda vencer a partir de leituras superficiais ou de descrições meramente factuais.

É no contexto da crise e das estratégias de recomposição do capitalismo, na passagem do século XX para o XXI, que despontam os debates acerca do desenvolvimento do território que emerge de construções afiançadoras do poder das escalas subnacionais, na mesma medida em que sopitam o sentido do Estado-Nação. Em movimento sôfrego, o global captura o local para uma trama monoescalar do desenvolvimento ${ }^{\mathrm{ii}}$. Nessa abordagem, o Estado-Nação é a sociedade que está sob o governo desse Estado.

De acordo com Brandão (2012) é fundamental projetar o desenvolvimento para além das escalas locais, ou seja, é necessário observar a importância das múltiplas escalas; é mister reconhecer a intransferível competência do Estado-Nação em relação às políticas macroeconômicas e o seu papel insubstituível na articulação e coordenação do pacto político no âmbito subnacional (a exemplo do pacto federativo).

O despropósito monoescalar no planejamento do desenvolvimento do território, a inobservância ou deslegitimação do Estado-Nação em suas prerrogativas macroeconômicas e políticas, o olhar de soslaio para a diversidade e a riqueza de seus 
sistemas naturais e de sua constituição étnico cultural, aferidas sob uma lente de alcance superlativo do ambiente construído, abeira-nos a uma cena de desigualdades econômicas, sociais, intrarregionais, entre outras, que persiste desde os primórdios da ocupação do território brasileiro.

Se o que se oferece como alternativa ameaça afrouxar os laços das potencialidades férteis de uma rara heterogeneidade, é fundamental se contrapor com iniciativas e construções próprias para o desenvolvimento do país.

\section{O desenvolvimento local sob a ótica das escalas}

Ante as estratégias do sistema capitalista e seus reflexos sobre o espaço, no que diz respeito a sua lógica de produção e fluxo na atualidade, o fortalecimento das escalas subnacionais e a construção de projetos de desenvolvimento, erguem-se posições de intercessão em nome de um modo de desenvolvimento que não se traduza unicamente em crescimento econômico, mas também em melhoria da qualidade de vida das pessoas e na garantia da preservação do meio ambiente. Surge, então, o chamado desenvolvimento local, cujo conceito ainda carece de consensos.

Diante das diversas ideias que atravessam, pois, o debate em torno do desenvolvimento local, destaca-se a interpretação de Oliveira (2001). É interessante e curioso observar a referência deste autor ao enfrentar o tema em uma de suas produções, que se intitula: "Aproximações ao enigma: que quer dizer desenvolvimento local?" (grifo nosso). Aliás, neste texto, ele é categórico em relação às perspectivas do desenvolvimento local ao defender que:

O desenvolvimento local é uma noção polissêmica, e necessariamente comporta tantas quantas sejam as dimensões em que se exerce a cidadania; qualquer tentativa, pois, de transformá-la em modelos paradigmáticos, está fadada ao fracasso (grifo nosso) (OLIVEIRA, 2001, p. 13)

Para Oliveira (2001, p. 15-16) que sustenta os seus argumentos ao propugnar o fracasso do desenvolvimento local no fato de estar baseado na desregulamentação, e: "[...] os chamados processos de desregulamentação ameaçam a cidadania e os direitos 
por ela gerados", na medida em que desresponsabilizam o Estado de cumprir atribuições a ele atinentes. Face a este aspecto ele questiona e antecipa o seu pessimismo: "O desenvolvimento local nessa acepção, pode resistir?”. Um segundo ponto levantado pelo autor, citando a experiência da Itália, diz respeito à incapacidade de $\mathrm{o}$ desenvolvimento local escapar aos "limites da racionalidade burguesa" e do capitalismo, fundamentado na propriedade privada, buscando o lucro e promovendo desigualdades.

Em um terceiro ponto, o autor (idem, p. 18) aponta que "o desenvolvimento local não entraria em contradição, em tensão, com a globalização, podendo ser, ao contrário, um de seus círculos concêntricos". Em síntese, para ele, o desenvolvimento local pode contribuir para acentuar a face perversa do capitalismo ao se basear na desregulamentação, na racionalidade burguesa e no enfraquecimento do Estado.

Por fim, Oliveira (idem, p. 21) reforça que "a luta pela cidadania é a forma mais moderna, contemporânea do conflito de classes". No contexto da luta pela cidadania, o autor (idem, p. 28) aproxima local de cidade e insere o conceito de megapólis, o que pode ser traduzido por cidade fortalecida na relação com outros poderes constituídos na construção do desenvolvimento. O autor defende outro projeto de desenvolvimento, "cuja condição é deslocar, também, o front da luta do econômico para o seu opositor, para o social e para o político".

As intervenções que visam ao desenvolvimento sugerem várias questões, algumas das quais são aqui trazidas para reflexão: $\mathrm{O}$ que fazer diante do caráter ambíguo do desenvolvimento? O que dizer àqueles que almejam a prosperidade, mas que se veem diante da inexorável frustração em alcançá-la? O que sucederá às atividades produtivas tipicamente locais, em particular as pequenas e médias, frente aos planos de desenvolvimentos entrantes? Essas, assim como tantas outras indagações se pronunciam e parece importante refletir sobre elas. Antes, porém, como exercício de aproximação da realidade, recordar-se-á de forma breve, como transcorre a posição da dimensão regional no desenvolvimento brasileiro.

Sobre dimensão regional, são significativas as contribuições de Lefebvre e Santos (1997, apud CRUZ, 2007). Com base nesses autores, a região será aqui abordada como uma construção social, material e simbólica. De acordo com os autores, dimensão 
regional é uma expressão da heterogeneidade e diferenciação territoriais decorrentes da espacialização do desenvolvimento capitalista, ou seja, das formas socioespaciais ${ }^{\text {iii }}$ que este assume.

\title{
O desenvolvimento brasileiro: uma abordagem sob a ótica da regionalização
}

A questão da dinâmica regional brasileira tem mobilizado diversos estudiosos a se debruçarem sobre o assunto e, a desconcentração da atividade industrial constitui recorte de grande interesse. Simões e Amaral (2011) comentam que vários conceitos têm sido criados por diferentes autores com o objetivo de contribuir para a elucidação do tema. Eles afirmam que Diniz (2006), em trabalhos recentes, expandiu a noção de “desenvolvimento poligonal" para "reconcentração poligonal”, podendo ser identificadas, de acordo Simões e Amaral, duas fases do processo de desconcentração:

\begin{abstract}
A primeira é caracterizada pela dispersão da indústria não só pelo entorno imediato da Região Metropolitana de São Paulo (RMSP) como também, marginalmente, por todos os estados brasileiros numa resposta ao esforço governamental dos anos 1970. A segunda fase, concomitantemente ao processo de abertura comercial, às privatizações e ao próprio ensaio de mudança da base tecnológica da indústria brasileira, estaria revelando a configuração de uma nova reconcentração em um polígono limitado por Belo Horizonte / Uberlândia / Londrina / Porto Alegre / Florianópolis / São José dos Campos / Belo Horizonte; além da própria RMSP. (SIMÕES, AMARAL, 2011, p. 557)
\end{abstract}

Tudo indica, no entanto, existir no plano analítico, um relativo consenso entre os estudiosos da dinâmica regional brasileira de que as alterações que resultaram na desconcentração das atividades econômicas e urbanas, a partir dos anos 1970, não foram suficientes para mudar radicalmente as desigualdades inter-regionais.

A compreensão da dinâmica dos deslocamentos regionais no país se tornou muito mais complexa a partir dos anos 1990, em razão de significativa relevância de fatores que se irromperam naquele cenário, tais como: a opção neoliberal ${ }^{\text {iv }}$ na condução da política social e econômica e o acirramento da concorrência nos mercados externos. Siqueira (2013, p. 84) enfatiza que a "diversificação da estrutura produtiva do país, a 
organização dos mercados de trabalho e a integração regional é interrompida". O que disso decorre, do ponto de vista das estratégias empresariais, é a adaptação às imposições da concorrência externa com base em uma atuação cada vez mais transescalar e, no que possui a marca das "políticas subnacionais de governo (estaduais e municipais)", as estratégias se voltam para a atração de investimentos pontuais e dirigidos a alguns setores específicos.

A partir dos anos 2003, a orientação das políticas oriundas do governo federal restabelece a relativa participação do Estado, os investimentos em áreas como saúde, educação, habitação etc. e, segundo Siqueira (idem, p. 85), "os investimentos programados ou em andamento" nas áreas de energia, petroquímica, infraestrutura, pelo que resulta das disputas políticas, acabam por beneficiar as áreas mais dinâmicas das macrorregiões e acentuar as diferenças sociais e econômicas no território brasileiro.

Esse período também é marcado por políticas voltadas para a elevação do valor real do salário-mínimo, transferência direta de renda, fatores que combinados entre si e somados a outros como a redução das taxas de desemprego em função do crescimento econômico são determinantes para demonstrar o potencial do mercado interno.

No ano de 2007, o Governo Federal estruturou um conjunto de projetos em diferentes setores dentre eles: infraestrutura urbana, transportes, comunicação e energia, com a previsão de aplicação de recursos públicos com a finalidade de fomentar o aumento de produtividade das empresas, de estimular os investimentos por parte do setor privado e reduzir as desigualdades entre as regiões. Essa política que repete a adoção do planejamento setorial, enquanto estratégia que marcou as políticas de governos nos anos pós-1970, ainda tem vários projetos em curso, mas que não são objetos de debate neste artigo. Neste estudo deter-se-á na criação da Rede Federal de Educação Profissional e Tecnológica e a expansão dessa rede, principalmente, por meio dos Institutos Federais de Educação, Ciência e Tecnologia.

\section{A Política de Expansão da Rede Federal e os Institutos Federais de Educação,} Ciência e Tecnologia: limites e possibilidades para o desenvolvimento 
Os Institutos Federais de Educação, Ciência e Tecnologia (IF) resultaram estruturalmente da reorganização dos Centros Federais de Educação Tecnológica (CEFET) e suas Unidades de Ensino Descentralizadas (UNED), das Escolas Agrotécnicas Federais (EAF) e de Colégios Técnicos Vinculados às Universidades Federais. Nesse processo, foram criados 38 (trinta e oito) IF e respectivos campi por meio da Lei $\mathrm{N}^{\mathrm{o}} 11.892 / 2008$. Essas Instituições (ilustradas espacialmente no território brasileiro, na Figura seguente) têm como atribuições a formação de profissionais nos diferentes níveis, desde os cursos de qualificação básica até os de pós-graduação "stricto sensu". Nesse intervalo, incluem-se cursos técnicos de nível médio, de graduação (licenciaturas, superiores de tecnologia e engenharias), o desenvolvimento da pesquisa aplicada e a ampliação e democratização do acesso ao conhecimento científico e tecnológico por meio de atividades de extensão.

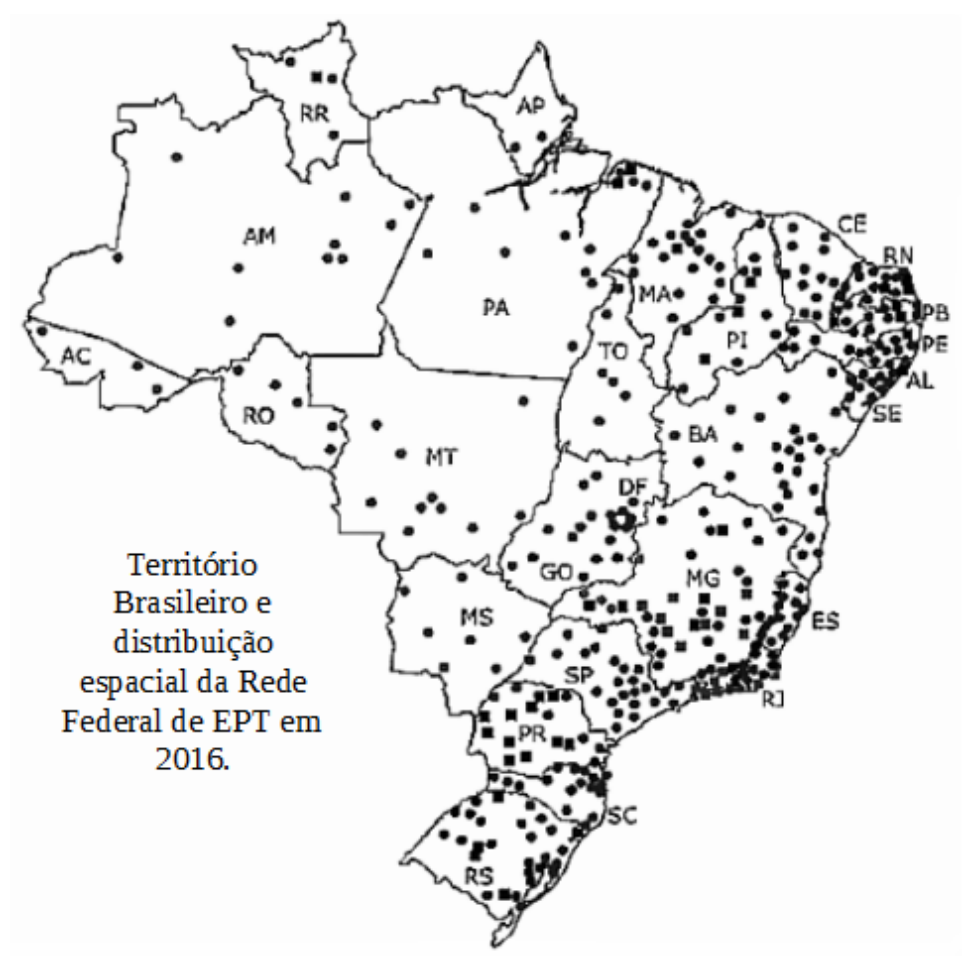

Fonte: MEC/SETEC, 2017. Organização do autor, 2017.

Cabe destacar que a lei 11.892/2008 implica estreita vinculação do papel dos IF ao desenvolvimento local, regional e nacional. Essas instituições, observadas como um 
todo reúnem características organizacionais e atribuições que configuram uma tipologia bastante singular, em que se destaca no seu campo de atuação a formação em áreas profissionais mais técnicas e práticas e a construção e difusão de conhecimentos que possam ser aplicados a mudanças mais imediatas. Essa formação, no entanto, preconiza a formação integral do homem e, por isso, integra como parte essencial no processo de formação, o desenvolvimento de um trabalho orientado por princípios que valorizem a capacidade crítica e reflexiva. Aliás, é importante registrar o caminho adotado por alguns países em relação ao ensino superior, ao criar instituições mais próximas de interesses locais e, em particular, relacionadas ao desenvolvimento econômico. Conforme observa Santos:

Na segunda metade do século XIX foram criadas universidades na Inglaterra nas grandes cidades industriais com a ideia de que poderiam acelerar o desenvolvimento econômico. [...] nos EUA, as ideias exportadas de outros países se mesclam com a cultura local dos Land Grant Colleges, que buscava o desenvolvimento agrícola e industrial daquele país. (SANTOS, 2013, p. 10)

Assim, na relação entre Educação Profissional e Tecnológica e Desenvolvimento, retoma-se à questão síntese deste trabalho, que é o lugar e o papel que cabe aos IF no contexto das políticas de desenvolvimento. Antecede ao mais específico, ou seja, à relação entre os IF e o desenvolvimento, alguns aspectos que se julga necessário considerar, na medida em que situam ou trazem a questão a partir de uma esfera mais ampla. Por exemplo, é preciso ter o cuidado em situar bem a relação entre educação, trabalho e desenvolvimento, de forma a distanciá-las de visões estereotipadas, simplistas ou idealizadas que, por vezes, com elevado conteúdo ideológico, responsabilizam ou culpabilizam o trabalhador diante do não-trabalho ou do não-emprego.

$\mathrm{Na}$ realidade, muitas vezes, o discurso político, com objetivos diversos, induz à compreensão do poder da formação profissional autodeterminar o trabalho e, por conseguinte, o desenvolvimento, o que reforça, no senso comum, a interpretação reducionista e falsa no interstício dessa relação. Para Manfredi,

As visões e representações sobre trabalho, sobre as profissões e sobre sua relação com escolarização são, na atualidade, muito variadas. $\mathrm{O}$ 
termo "trabalho" normalmente vem associado à ideia de emprego, ou seja, de atividade remunerada. As relações entre trabalho e escola, por sua vez, expressam visões ambíguas e idealizadas. De um lado, estão as representações que denotam negatividade, mediante a subestimação da importância da escola e a supervalorização da experiência, dos saberes e do savoir faire adquiridos no mundo do trabalho; [...] de outro, estão as visões que superestimam a importância da escola como veículo de formação profissional e de ingresso no mercado, $[\ldots]$ (MANFREDI, 2002, p. 31)

A relação entre educação, inclusive a que se destina à qualificação profissional, e trabalho se põe no campo do direito das pessoas; o que dela deriva, o que ela potencializa e se põe em um complexo campo de relações cujos fatores políticos, econômicos, sociais e culturais, são determinantes e determinados, são causa e consequência. Neste sentido, a educação e, em particular, a formação para o trabalho deve se vincular de forma incondicional a uma perspectiva, de natureza política e social mais ampla, conformada à irrefutável precedência do direito das pessoas.

A abrangência territorial dos IF favorece a sintonia com a diversidade regional, destino essencial de seu trabalho e, ao mesmo tempo, possibilita que essas instituições enxerguem, ou se coloquem diante de múltiplas escalas. É importante uma atuação permanentemente articulada, contextualizada e sistêmica, legitimada por sua natureza pública e estatal, e que diante de hierarquias e prerrogativas dos diferentes atores e representações presentes e envolvidas no processo de desenvolvimento procurem responder à necessidade de se forjar e fomentar o desenvolvimento a partir de uma demanda que seja socialmente plena; que considere as diversas representações sociais que a sociedade tem a respeito do seu papel, desde as oriundas da chamada produção elaborada, os médios e pequenos empreendimentos e os movimentos sociais, traduzindo-se, assim, em ações que resultem do efetivo diálogo.

A autonomia dos IF é essencial para o que Brandão (2004, p. 60) considera importante na construção de estratégias multiescalares: "Encontrar a escala adequada que defina determinado campo onde a decisão deve ser tomada. Buscar a escala de observação adequada para a tomada dos fenômenos sobre os quais se deseja intervir".

A criação dos IF, nessa perspectiva, apresenta enormes possibilidades no que se refere à contribuição dessas instituições para o desenvolvimento do país, na mesma 
medida, porém, é preciso reconhecer e observar que limites se lhes impõem.

Obviamente, além das dificuldades advindas de fatores determinantes pelas aceleradas, crescentes e rápidas mudanças em um contexto mais amplo, que se complexificou ao ponto de carregar de incertezas o presente, tendo em vista limitações e insuficiências dos modelos analíticos tradicionais, que trazem implicações para todas as instituições, no caso particular dos IF, é fundamental destacar que eles não estão consolidados e a sua afirmação no Sistema Educacional Brasileiro está sujeita à combinação e a articulação de diversos fatores, dentre esses o reconhecimento pelos diferentes atores envolvidos nesse processo do papel estratégicos que essas instituições podem assumir no desenvolvimento e no fortalecimento da cidadania.

\section{Considerações Finais}

Neste artigo buscou-se destacar as políticas da Educação Profissional e Tecnológica (EPT) e sua relação com o desenvolvimento, com especial atenção aos Institutos Federais de Educação, Ciência e Tecnologia (IF). Nesta análise, procurou-se "fugir" do sentido estático e tradicional de desenvolvimento, situando no plano do que tem sobressaído que é o debate sobre o papel e as possibilidades das escalas subnacionais.

Obviamente não se pretendeu responder, ou mesmo encaminhar, posição conclusiva, mas ao contrário, o que se objetivou foi tirar de um lugar muito estabelecido, numa relação de causa e efeito, o vínculo entre EPT e desenvolvimento, na mesma medida em que se procurou observar, criticamente, o que tem sido, em alguns casos apresentados e de forma desproporcional, os poderes locais ou subnacionais.

A expansão da Rede Federal, sem dúvida, caminhou na direção das políticas que valorizaram as dimensões regionais, ou seja, o movimento de desconcentração do desenvolvimento do território nacional. Ao lado desse processo foram criados os IF que têm atribuições e grau de autonomia que elevam as possibilidades de ações em favor do desenvolvimento. Com tudo isso, alerta-se para o cuidado de não considerar absoluto o poder dessas instituições e dos atores envolvidos nas escalas subnacionais. Antes, 
precisam ser olhadas de forma discreta, tendo em vista que se vive um período em que as decisões sobre desenvolvimento ultrapassam as escalas nacionais.

Por derradeiro, destaca-se, ainda, a importância de se refletir em profundidade sobre o papel político dessas instituições quando o que se pretende é o desenvolvimento que considere, valorize e fortaleça a sustentabilidade da vida dos cidadãos em suas múltiplas relações e representações a respeito de sua efetiva participação e de seus direitos. Sem essa reflexão e cuidado, a EPT não escapará à formação de trabalhadores sob a égide e diretrizes exclusivas do mercado.

\section{Referências}

BRANDÃO, Carlos Antônio. Teorias, Estratégias e Políticas Regionais Urbanas Recentes: anotações para uma agenda do desenvolvimento territorializado. Revista Paranaense de Desenvolvimento, Curitiba-PR, p. 57-76, jul/dez. 2004. Disponível em: http://carlosbrandao.org/publicacoes/\#.V7rjDDXRvHE. Acesso em: 19 de ago. de 2016.

. Desenvolvimento, territórios e escalas espaciais: levar na devida conta as contribuições da economia política e da geografia crítica para construir a abordagem interdisciplinar. In: RIBEIRO, Maria Teresa F. e MILANI, Carlos R. S. (Org.). Compreendendo a complexidade socioespacial contemporânea: o território como 
categoria de diálogo interdisciplinar. Salvador, Editora da UFBA, 2009, p. 150-185. Disponível em: http://carlosbrandao.org/publicacoes/\#.V6vWrDXRvHE. Acesso em: 10 de ago. de 2016.

Território e desenvolvimento: as múltiplas escalas entre o local e o global. 2. ed. Campinas: Editora Unicamp, 2012.

BRASIL. Lei $\mathrm{N}^{\circ}$ 11892, de 29 de dezembro de 2008. Institui a Rede Federal de Educação Profissional, Científica e Tecnológica, cria os Institutos Federais de Educação, Ciência e Tecnologia, e dá outras providências.

CRUZ, José Luís Vianna. Espaço social, ambiente construído e reprodução social. Campos dos Goytacazes: UCAM-Campos, Série UCAM-Região. ano III, n. 10, p. 36, maio/2007.

DINIZ, Clélio Campolina. A Busca de um Projeto de Nação: O Papel do Território e das Políticas Regional e Urbana. Revista EconomiA. Brasília, v.7, n. 4, p. 1-18, dezembro de 2006.

MANFREDI, Silvia Maria. Educação profissional no Brasil. São Paulo: Cortez, 2002.

MEC/SETEC - Rede Federal de Educação Profissional, Científica e Tecnológica. 2017. Disponível em: <http://redefederal.mec.gov.br/instituicoes>. Acesso em: $12 \mathrm{de}$ fev. 2017.

OLIVEIRA, Francisco de. Aproximações ao enigma: o que quer dizer desenvolvimento local? São Paulo. Pólis; Programa Gestão Pública e Cidadania/EAESP/FGV, p. 40, 2001. Disponível em: http://www.polis.org.br/uploads/1144/1144.pdf. Acesso em: 08 de ago. de 2016.

SANTOS, Milton. Da Totalidade ao Lugar. São Paulo: Editora da Universidade de São Paulo, 2008.

SIMÕES, Rodrigo; AMARAL, Pedro V. Interiorização e Novas Centralidades Urbanas: uma visão prospectiva para o Brasil. EconomiA. Brasília, v. 12, n. 3, p. 553-579, set./dez. 2011. 


\section{Notas}

De acordo com o Art. $1^{\circ}$ da Lei $\mathrm{N}^{\circ}$ 11.892, de 29 de dezembro de 2008, a Rede Federal de Educação Profissional, Científica e Tecnológica é constituída pelas seguintes instituições: Institutos Federais de Educação, Ciência e Tecnologia (Institutos Federais), Universidade Tecnológica Federal do Paraná (UTFPR), Centros Federais de Educação Tecnológica Celso Suckow da Fonseca (CEFET-RJ) e de Minas Gerais (CEFET-MG), Escolas Técnicas Vinculadas às Universidades Federais e o Colégio Pedro II. Seria legal colocar aqui os números da Rede em 2016, o que acha? Entre 2003 e 2016, o Ministério da Educação concretizou a construção de mais de 500 novas unidades referentes ao plano de expansão da educação profissional, totalizando 644 campi em funcionamento (MEC/SETEC, 2017).

ii Sobre Estado-Nação, consideramos relevante esclarecer que a expressão é aqui tomada no sentido de país e no que se refere à organização política e administrativa de um território geograficamente delimitado.

iii Optamos pela grafia "sócio-espacial" considerando a defesa de Souza (2009, p.24-25) de que existe a possibilidade de dupla grafia, no caso de "Socioespacial", sem hífen, "se refere somente ao espaço social" e "sócio-espacial", com hífen, "diz respeito às relações sociais e ao espaço, simultaneamente (abrangendo, diretamente, a dinâmica da produção do próprio espaço, no contexto da sociedade concreta como totalidade)".

iv Neoliberalismo: termo associado ao liberalismo clássico e a medidas onde Estado se coloca de forma parcial no plano econômico. Há ampla liberdade de mercado e redução da participação do Estado no financiamento e implementação das políticas. Um de seus marcos originais, é o período da I Ministra do Reino Unido (1979-1990). 